\title{
КЛИНИЧЕСКИЕ ОСОБЕННОСТИ РАЗВИТИЯ ДЕПРЕССИИ КАК ПРЕ- ДИКТОРА ОСЛОЖНЕННЫХ ФОРМ МИГРЕНИ
}

\author{
${ }^{1}$ Саноева М.Ж.*, ${ }^{2}$ Саидвалиев Ф.С. \\ 'Бухарский Государственный Медицинский Институт, Бухара, Узбекистан; \\ ${ }^{2}$ Ташкентская медицинская академия, Ташкент, Узбекистан
}

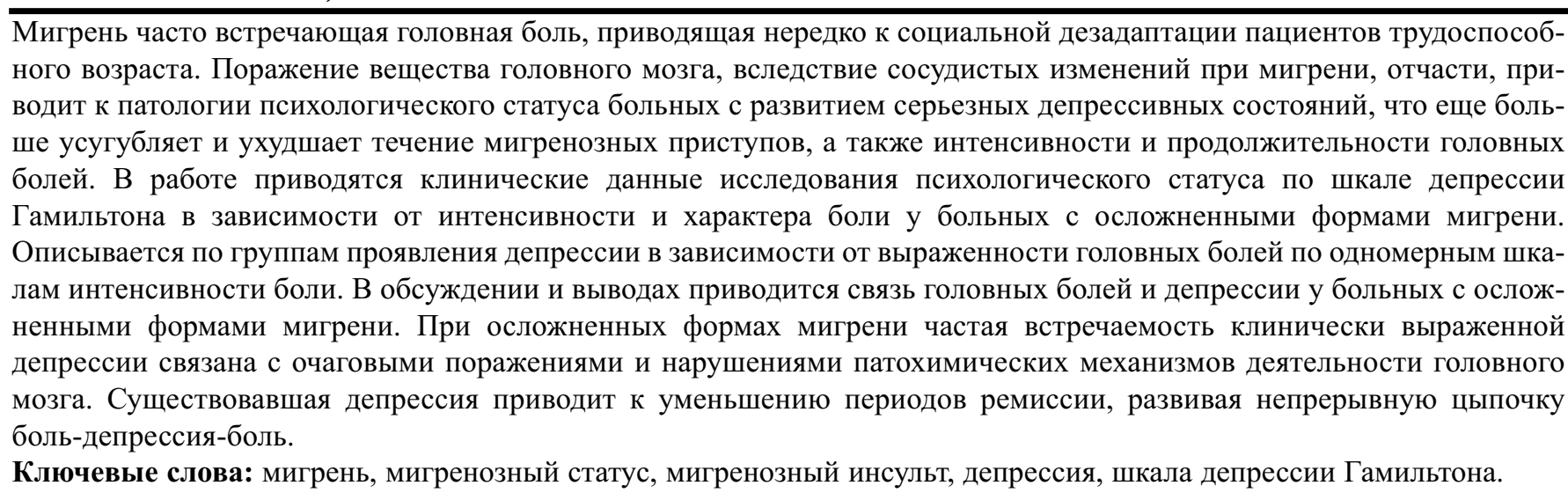

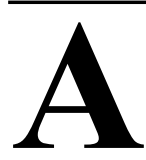

ктуальность проблемы. Среди первичной головной боли особое место отводится одной из распространенных сосудистых головных болей - мигрени, которой страдают до 12\% населения земного шара [2,5,6,13]. Мигрень - это хроническое неврологическое заболевание, различающееся по частоте периодов обострений, тяжести течения и влиянию на качество жизни пациентов $[4,8,9]$. Чувство ожидания головной боли при мигрени приводит к эмоциональной нестабильности, капризности, вплоть до развития депрессии, что чревато развитием психологической дезадаптации пациентов $[1,7,10]$. По данным исследований The American Migraine Prevalence and Prevention (AMPP), в отношении 38,8\% пациентов с мигренью требуется профилактический подход $[1,11,13,14]$. Для некоторых пациентов проблема головной боли не является особенно значимой, хоть и мучаются годами, вплоть до развития осложнений, в связи с чем, при проведении статистической обработки число пациентов с головными болями, в частности с мигренью, остаются относительными [12,18,20,23].

Всемирной организацией здравоохранения мигрень включена в список 19 хронических заболеваний, в наибольшей степени нарушающих социальную адаптацию пациентов $[15,18,20,22]$. Пациенты с мигренью страдают годами, пробуют имеющиеся традиционные про- тивоболевые препараты и не получают ожидаемого эффекта, что приводит к развитию депрессии, эмоциональной нестабильности, нарушению физиологических биоритмов: сон - пробуждение, утрачивается желание радоваться, общаться с близкими, делать обычную повседневную работу, исчезает интерес к собственному существованию как личности [7,15,17,21,24]. Длительность течения и тяжесть головных болей при мигрени приводит к развитию депрессии в два раза чаще, чем у людей не имеющих приступов мигрени [3,19,25]. Исследователи (University of Toronto) обнаружили, что среди мужчин депрессия при мигренозных головных болях составляет 8,4\%, тогда как среди женщин 12,4\%. Женщины, страдающие от мигрени, более подвержены эмоциональным перепадам и депрессивному настроению [26,27]. По американским данным 2013 года, мигрень значительно повышает риск развития депрессии у женщин, о чем свидетельствует опрос 36000 респондентов. Как показал анализ данных, женщины, у которых была мигрень, на 36\% чаще жаловались на депрессию. Пациентки, которые страдали мигренью с аурой страдали от эмоциональных проблем на 43\% чаще, чем женщины, никогда не испытывающие мигрень [16,28,29]. После анализа приведенных данных, мы решили провести собственное наблюдение психологического статуса, в зависимости от выраженности боли при

*e-mail: matlyubadoct70@mail.ru 
осложненной мигрени.

Цель исследования - изучить психологический статус больных с осложненными формами мигрени в зависимости от интенсивности и длительности головных болей.

Материал и методы исследования. Обследованы 106 больных (100\%) в возрасте от 26 до 46 лет (средний возраст $36 \pm 2,8$ года), из них $38(40,3 \%)$ с мигренозным статусом (1-я группа), 46 (48,8\%) с хронической мигренью (2- я группа), 22 (23,3\%) с мигренозным инсультом (3-я группа). Был проведен анализ клинико-неврологических данных, результатов психологического тестирования с использованием шкалы Гамильтон для оценки депрессии (HDRS - 21). Для оценки характера и интенсивности боли использовали шкалы одномерной интенсивности боли (рис. 1) - цифровая рейтинговая шкала (NRS), вербальная рейтинговая шкала (VRS) и визуальная аналоговая шкала (VAS)

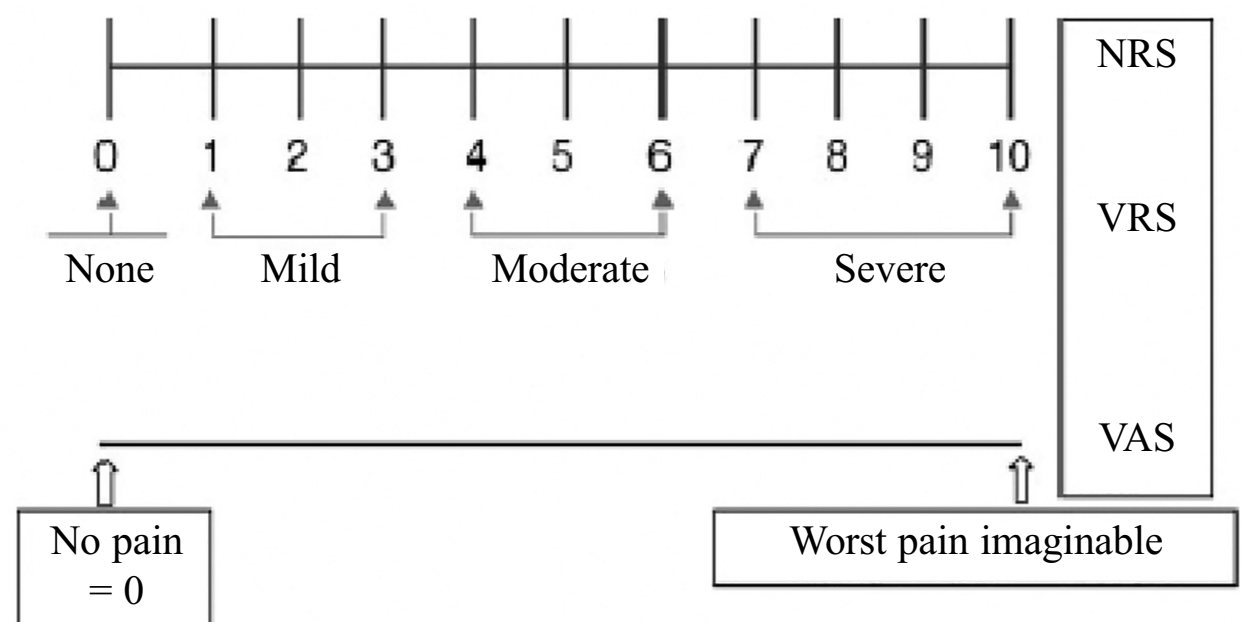

\section{Рис. 1. Одномерные шкалы интенсивности боли: цифровая рейтинговая шкала (NRS), вербальная рейтинговая шкала (VRS) и визуальная аналоговая шкала (VAS)}

При этом «отсутствие боли» по шкале VRS было равно 0 по шкале NRS, «незначительная головная боль» - 1-3 по линейной градации, «умеренная головная боль» - 4-6, тогда как по шкале ВАШ эти градации отмечались как «отсутствие головных болей», 7-10 линейных градаций по шкале NRS - как «сильные головные боли» по шкале VRS и как «наихудшие головные боли» по шкале ВАШ. Данные ВАШ сравнивали с лицевыми шкалами боли (faces pane scale). Исследование психологического статуса по данным шкалы Гамильтон (HDRS-21) у каждого больного занимало 20-22 мин. Время оценки определяли, как «в течение последней недели». У больных, которые отклонялись от ответов, подключали их родственников, при этом прямые вопросы были сведены к минимуму. Повторные исследования по шкале Гамильтон после лечения проводили и оценивали без предварительного просмотра предыдущего измерения, на чистом регистрационном листе.
Результаты и обсуждение. При анализе данных клинического исследования выявили следующее: в 1-й группе головные боли приступообразного, пульсирующего характера по типу гемикрании отмечались у $32(84,2 \%)$ больных, во 2-й - у $32(69,6 \%)$, в 3 -й - у 9 (41\%), двусторонние головные боли - соответственно у 4 (10,5\%), 5 (10,9\%) и 10 (45,5\%); боли приступообразного характера в области затылка - у 2 (5,3\%), 5 (10,9\%) и 1 (4,6\%). Тяжесть в голове - у 2 (9,1\%) больных 3-й группы. Приступы мигрени часто сопровождались фотофобией: в 1-й группе - у 37 (97,4\%), во 2-й - у 41 $(89,1 \%)$, в 3-й - у 18 (81,8\%). Фонофобией и гиперакузией во время приступа в 1-й группе страдали 35 (92,1\%) больных, во 2-й - 44 (95,7\%), в 3-й - 20 (90,9\%); гиперосмией - соответственно $30(78,9 \%), 22(47,8 \%)$ и $7(31,8 \%)$; тошнотой, иногда сопровождающейся рвотой, - 28 (73,7\%), $18(39,1 \%)$ и $8(36,4 \%)$; потерей пространственной ориентации и головокружением - $8(21,1 \%), 16$ $(34,8 \%)$ и $21(95,5 \%)$. Часто наблюдалась задерж- 
ка стула, чувство переполнения желудка и переедания - соответственно у 12 (31,6\%), 22 (47,8\%) и $6(27,3 \%)$; отказ от пищи и снижение аппетита у $22(57,9 \%), 24(52,2 \%)$ и $18(81,8 \%)$; раздражительность по любому поводу - у 34 (89,5\%), 22 (47,8\%) и 12 (54,5\%); угнетенное, подавленное настроение с общей вялостью - у 18 (47,4\%), 38 $(82,6 \%)$ и $20(90,9 \%)$. В 1-й группе сонливость после мучительных приступов головных болей мучала 22 (57,9\%) больных, во 2-й - отмечалось у 38 (82,6\%) больных вне зависимости от приступов, а в 3-й группе она была постоянного характеpa - у 18 (81,8\%). Бессонницей страдали - соответственно 13 (34,2\%), 6 (13\%) и 7 (31,8\%) больных. В таб. 1 приведены данные субъективных ощущений больных.

Таблица 1

\section{Субъективные симптомы больных с осложненными формами мигрени по группам}

\begin{tabular}{|l|l|l|l|}
\hline \multirow{2}{*}{ Клинические симптомы } & \multicolumn{3}{|c|}{ Группа больных } \\
\cline { 2 - 4 } & \multicolumn{1}{|c|}{$1-я$} & \multicolumn{1}{c|}{ 3-я } & \multicolumn{1}{|c|}{} \\
\hline Головные боли & $38(100)$ & $46(100)$ & $20(91)$ \\
\hline Фотобия & $37(97,4)$ & $41(89,1)$ & $18(81,8)$ \\
\hline Фонофобия & $35(92,1)$ & $44(95,7)$ & $20(90,9)$ \\
\hline Гиперосмия & $30(78,9)$ & $22(47,8)$ & $7(31,8)$ \\
\hline Тошнота с рвотой & $28(73,7)$ & $18(39,1)$ & $8(36,4)$ \\
\hline $\begin{array}{l}\text { Нарушение координации во время } \\
\text { приступов головных болей }\end{array}$ & $8(21,1)$ & $16(34,8)$ & $21(95,5)$ \\
\hline Снижение аппетита & $22(57,9)$ & $24(52,2)$ & $18(81,8)$ \\
\hline Симптомы гастропатии & $12(31,6)$ & $22(47,8)$ & $6(27,3)$ \\
\hline Дисфория & $34(89,5)$ & $22(47,8)$ & $12(54,5)$ \\
\hline Угнетённое настроение & $18(47,4)$ & $38(82,6)$ & $20(90,9)$ \\
\hline Сонливость & $22(57,9)$ & $38(82,6)$ & $18(81,8)$ \\
\hline Бессонница & $13(34,2)$ & $6(13)$ & $7(31,8)$ \\
\hline
\end{tabular}

Примечание: в скобках указан процент

Согласно шкале Гамильтона (HDRS- 21), отсутствие достоверно выраженных симптомов (от 7 до 16 баллов) тревоги и депрессии выявлялось у незначительного количества больных с осложненными формами мигрени; соответственно у $4(10,5 \%), 3(6,5 \%)$ и 1 (4,6\%). Субклинически выраженная депрессия (от 17 до 27 баллов по шкале Гамильтона) была выявлена на 20\% чаще при хронической мигрени, чем у больных с мигренозным статусом, и на $40 \%$ чаще, чем при мигренозных инсультах. Так, в 1-й группе она наблюдалась у 18 (47,4\%) больных, во 2-й - у 32 $(66,7 \%)$, в 3-й - у 5 (22,7\%). Клинически выраженная депрессия (более 27 баллов) выявлялась на 20\% чаще у больных с мигренозным статусом, чем у больных с хронической мигренью, а при мигренозных инсультах она встречалась на $40 \%$ чаще, чем при хронической мигрени. Так, в 1-й группе она отмечалась у $16(42,1 \%)$ больных, во 2 -й - у $11(23,9 \%)$ и в $3-и ̆-$ у $16(72,7 \%)$. В рис. 2 приводим сопоставление выраженности депрес- сии между группами.

По одномерным шкалам интенсивности боли отмечалась незначительная головная боль (по VRS, равная по данным NRS от 1 до 3 - линейной градации и нет боли по шкале VAS, а по сравнению с лицевой шкалой (FPS) она равна была 1-2 баллам) у 3 (7,9\%) больных 1-й группы, $13(28,3 \%)$ пациентов 2-й группы и у $6(48,3 \%)$ больных 3-й группы, при этом выраженность депрессии у данных больных оценивалась как отсутствие депрессии у всех 3 (7,9\%) больных 1й группы, у 2 (5,3\%) пациентов 2-й группы и у 1 (4,5\%) больного 3-й группы. Субклиническая стадия депрессии отмечалась у 10 (26,3\%) больных 2-й группы, у всех 5 (22,7\%) пациентов 3-й группы; клинически выраженная депрессия выявлялась у 1 (2,17\%) больного 2-й группы.

Умеренная головная боль (по данным шкалы VRS от 4 до 6 линейной градации по данным NRS, отсутствие боли по данным VAS, и по сравнению с лицевой шкалой (FRS) равняется 3 


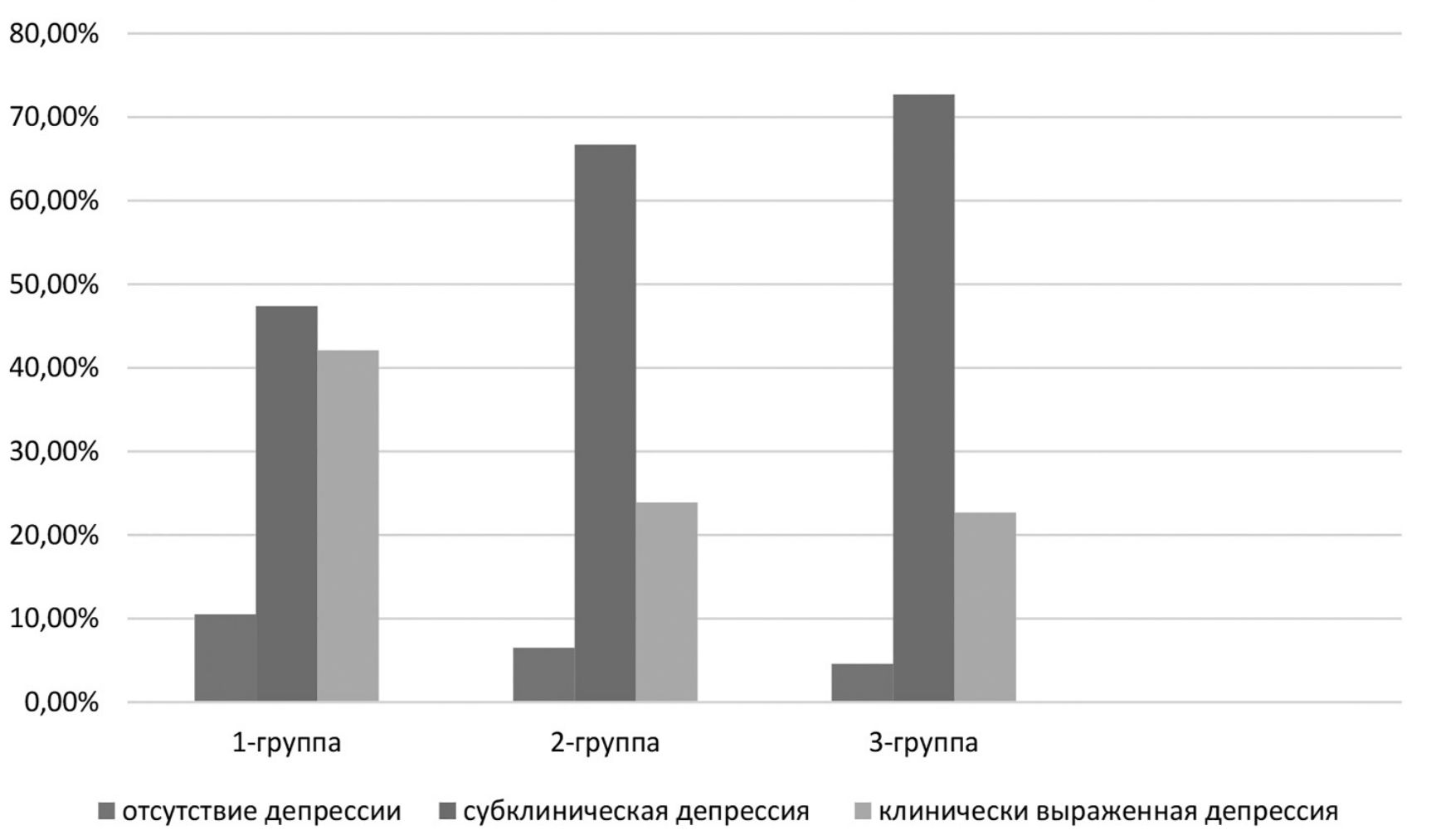

Рис. 2. Выраженность депрессии по шкале Гамильтон

баллам) выявилась в 1-й группе у $8(21,1 \%)$ больных, во 2-й - у 21 (45,7\%), в 3-й - у 12 (54,6\%); при этом отсутствие депрессии отмечалось у 1 $(2,6 \%)$ больного 1-й группы, 1 (2,2\%) пациента 2й группы; субклиническая стадия депрессии наблюдалась у 8 (21,1\%) больных 1-й группы, 14 (30,4\%) пациентов 2-й группы, 3 (13,6\%) больных 3-й группы; клинически выраженная депрессия выявлялась соответственно у 6 $(15,8 \%), 4(8,7 \%)$ и $5(27,7 \%)$ человек.

Сильные головные боли (по шкале VRS, 7-10 линейных градаций по NRS, и 7-10 мерных отрезков по шкале VAS, a со сравнением с лицевыми шкалами 4-5 балла) в 1-й группе наблюдали у $27(71,1 \%)$ больных, во 2-й - у 14 $(30,4 \%)$, в 3 -й - у 2 (9,1\%); при этом субклиническая стадия депрессии - соответственно у 10 $(26,3 \%), 22(47,8 \%)$ и $3(13,6 \%)$; клинически выраженная депрессия - у 10 (26,3\%), 6 (13,1\%) и 11 (50\%) пациентов.

Результаты клинического исследования позволяют сделать вывод, что, наблюдая за развитием патологии психологического статуса больных с осложненными формами мигрени, можно определить влияние головной боли на степень развития депрессии. Головная боль может оказаться причиной развития и усугубления симптомов депрессии и развития социальной дезадаптации больных с осложненными формами мигрени как из-за собственно головной боли, и, по-видимому, так и из-за развития патобиохимических механизмов поражения самого вещества головного мозга. Как видно из приведенных клинических данных, при мигренозном статусе отмечается субклиническая и клинически выраженная депрессия при сильных головных болях, при хронической мигрени наблюдается превалирование субклинической депрессии при умеренной головной боли, которое, по-видимому связано с длительностью головных болей и короткими периодами ремиссии. При мигренозных инсультах частая встречаемость клинически выраженной депрессии связана с очаговыми поражениями и нарушениями патохимических механизмов деятельности головного мозга. Существовавшая депрессия усугубляет интенсивность болевого синдрома и его продолжительность, уменьшает периоды ремиссии, развивает непрерывную цепочку боль-депрессияболь. 


\section{Выводы:}

1. Развитие депрессии у больных с осложненными формами мигрени, приводящее к социальной дезадаптации пациентов, усугубляет клиническое течение, усиливает интенсивность головных болей, удлиняет период болевого синдрома.

2. По обратной цепочке интенсивность и длительное существование головных болей, и корот-

\section{ЛИТЕРАТУРА - REFERENCES - ӘDӘВIYYYAT}

1. Амелин А.В. Профилактика мигренозных пароксизмов. //- В кн.: Новые технологии в диагностике, лечении и реабилитации неврологических заболеваний. - СПб., 2010. 2. Батышева Т.Т., Костенко Е.В., Ганжула ПА. и др. Комплексная программа вторичной профилактики инсульта: место препарата Вазобрал. Cons. Med., 2007; 9. 3. Григорьева В.Н., Густов А.В., Корнилова Л.Е., Куликова О.А. Журн. невропатол. и психиатр. им. С.С. Корсакова, 2003, 103(12), с. 20-25.

4. Международная классификация головных болей: - Пер. В.В. Осиповой, Т.Г. Вознесенской. - Изд. 2-е. - 2003. $219 \mathrm{c}$.

5. Мищенко Т.С., Мищенко В.Н. Современная диагностика и лечение неврологических заболеваний. Справочник врача «Невролог». - ООО «Доктор-Медиа», 2010, с. 6574.

6. Мозолевский Ю.В., Успенская О.В., Черкашин А.В. Мигренозный инсульт. Боль 2006; 4(13): 25-30.

7. Морозова О.Г. Мигрень: вопросы коморбидности и дифференциальной диагностики // Здоров'я України. 2010. — № 4. - С. 19-20.

8. Морозова О.Г. Здоров’я України, 2010, № 4, с. 19-20.

9. Кадыков А.С., Шахпаронова Н.В., Манвелов Л.С. Справочник по головной боли - Москва. Милкош, 2005. — 170 с.

10. Сучасна діагностика і лікування у неврології та психіатрії / Под ред. Т.С. Міщенко, В.С. Підкоритова. - Кнев: ТОВ «Доктор-Медіа», 2008. - 624 с.

11. Табеева Г.Р. Профилактика мигрени. Руководство - М.: Пульс, 2008.

12. Шток В.Н. Головная боль. - М.:ООО «Мединформагенство», 2007. - 472 с.

13. Яхно Н.Н., Парфенов В.А., Алексеев В.В. Головная боль при цереброваскулярных заболеваниях. - В кн: Головная боль. М., 2000, с.73-78.

14. Arboix A, Massons J, Oliveres M. Headache in acute cerebrovascular disease: a prospective clinical studying 240 patients. Cephalagia. 1994; 14:37-40.

15. American Academy of Neurology: Evidence-based guidelines for migraine headache in the primary care setting: pharmacological management for prevention of migraine. Accessed online November 8, 2005. кие периоды ремиссии между ними могут стать причиной развития глубоких депрессий вплоть до снижения или отсутствия работоспособности лиц трудоспособного возраста.

3. В связи с этим необходимо разработать пути профилактической и реабилитационной терапии депрессии при мигрени для разрыва цепочки боль-депрессия-боль.

16. Boska M.D., Welch K.M.A., Bar-ker P.B. et al. Contrasts in cortical magnesium, phospholipid and energy metabolism between migraine syndromes // Neuro- logy. - 2002. - V. 58. - P. 1227-1233.

17. Charles A., Brennan K.C. Cortical spreading depression - new insights and persistent questions // Cephalalgia. 2009. - V. 29. - P. 1115-1124.

18. Connor K.M., Shapiro R.E., Diener H.C. et al. Randomized, controlled trial of telcagepant for the acute tretment of migraine // Neurology. — 2009. — 22. — 970-977.

19. Gasbarri A., Armone B., Pompili A. et al. Emotional memory and migraine: Effects of amitriptyline and sex related difference // Behav. Brain. Res. - 2008. - 189. - 220-225.

20. Goadsby P.J., Lipton R.B., Ferrari M.D. Migraine - current understanding and treatment // New Engl. J. Med. 2002. - 346. - 257-70.

21. Goadsby P.J. Migraine, aura, and cortical spreading depression: why are we still talking about it? // Ann. Neurol. - 2001. - 49. - 4-6.

22. Kruit MC, van Buchem MA, Hofman PA Migraine as a risk factor for subclinical brain lesions. JAMA 2004; 291:427-34.

23. Kurth T, Slomke MA, Kase CS. Migraine, headache and the risk of stroke in women: a prospective study. Neurology 2005; 64:1020-6.

24. Olesen J., Lipton R.B. Migraine classification and diagnosis. International Headache Society criteria // Neurology. 1994. - 44 (Suppl. 4). - 6-10.

25. Solomon S. Migraine diagnosis and clinical symptomatology // Headache. - 1994. - 34. - S8-12.

26. Stang PE, Carson AP, Rose KM. Headache, cerebrovascular symptoms and stroke: the Atherosclerosis Risk in Communities Study. Neurology 2005; 64:1573-7.

27. Swartz RH, Kern RZ. Migraine is associated with magnetic resonance imaging white matter abnormalities: a metaanalysis. Arch Neurol 2004; 61:13668.

28. Scher AI, Terwindt GM, Picavet HSJ. Cardiovascular risk factors and migraine. Neurology 2005; 64: 614-20.

29. Welch KMA, Bousser MG, Bogouslavsky J. Migrainous infarction and migraine triggered epilepsy. In: Olesen J, Goads-by PJ, Ramadan NM (eds). The Headaches. 3rd ed. Lippincott Williams \& Wilkins, 2006:599-612. 


\title{
XÜLASə
}

\section{MIQQRENIN AĞIRLAŞMIŞ FORMALARININ PREDIKTORU KIMII DEPRESSIYYANIN İNKISSAFININ KLINIIK XÜSUSIYYOTLӘRI}

\author{
'Sanoyeva M.J.*, ${ }^{2}$ Saidaliyev F.S. \\ ${ }^{1}$ Buxara Dövlat Tibb İnstitutu, Buxara, Ğzbəkistan; \\ ${ }^{2}$ Daşkənt Tibb Akademiyası, Daşkənt, Özbəkistan
}

Miqren çox vaxt əməkqabiliyyətli yaş dövründə pasiyentlərin sosial dezadaptasiyasına gətirib çıxaran, tez-tez rast gəlinən baş ağrısıdır. Miqren zamanı damar dəyişiklikləri nəticəsində beyin maddəsinin zədələnməsi çox vaxt ciddi depressiv vəziyyətlərin inkişafi ilə xəstələrin psixoloji statusunun patologiyasına səbəb olur, bu da miqrenoz tutmaların gedişini, həm də baş ağrılarının intensivliyini və davametmə müddətini daha da dərinləşdirir və pisləşdirir. Təqdim edilmiş elmi işdə miqrenin ağırlaşmış forması olan xəstələrdə ağrının intensivliyi və xarakterindən asılı olaraq, Hamiltonun depressiya şkalası ilə psixoloji statusun tədqiqinin klinik nəticələri göstərilir. Depressiyanın yaranması ağrının intensivliyinin eyniölçülü şkalaları ilə baş ağrılarının qabarıqlığından asılı olaraq qruplarla təsvir edilir. Müzakirə və nəticələr bölməsində miqrenin ağırlaşmış formaları olan xəstələrdə baş ağrıları və depressiyanın əlaqəsi təqdim edilir. Miqrenin ağırlaşmış formaları zamanı klinik qabarıq depressiyanın tez-tez rast gəlinməsi baş beynin fəaliyyətinin patokimyəvi mexanizmlərinin pozuntuları və ocaqlı zədələnmələri ilə əlaqədardır. Mövcud depressiya fasiləsiz ağn1-depressiya-ağrı zəncirini yaradaraq, remissiya dövrlərinin azalmasına səbəb olur.

Açar sözlər: miqren, miqrenoz status, miqrenoz insult, depresiya, Hamiltonun depressiya şkalası.

\section{SUMMARY}

\section{CLINICAL FEATURES OF THE DEVELOPMENT OF DEPRESSION AS A PREDICTOR OF COMPLICATION FORMS OF MIGRAINE}

\author{
${ }^{1}$ Sanoyeva M.J. ${ }^{2}$ Saidvaliyev F.S. \\ ${ }^{1}$ Bukhara State Medical Institute, Bukhara, Uzbekistan; \\ ${ }^{2}$ Tashkent Medical Academy, Tashkent, Uzbekistan
}

\begin{abstract}
Migraine is one of the common type of headache of ten times leading patients of working age to social maladjustment. It has been long studied by scientists all over the world and some aspects should be matter of further study. Brain damage due to vascular pathology in migraine partly cause pathology of psychological status with the development of severe depression which in turn further aggravate and worsen migraine attack and also intensity and duration of headache. The report provides data of psychological status examination according to Hamilton Rating Scale based on intensity and the character of headaches in patients with complicated forms of migraine. One out of them is severe depression, which involves focal lesion and pathochemical disturbances in brain activity. Existed depression might worsen headache intensity and duration leading to reduction of remission periods, contributing continuous chain so called pain-depression-pain.
\end{abstract}

Key wards: migraine, status migrainosus, migrainous stroke, depression, Hamilton Rating Scale for Depression.

Redaksiyaya daxil olub: 14.06 .2018

Çapa tövsiya olunub: 09.07.2018

Rayçi: t.ü.e.d. Məmmadbəyli A.K. 